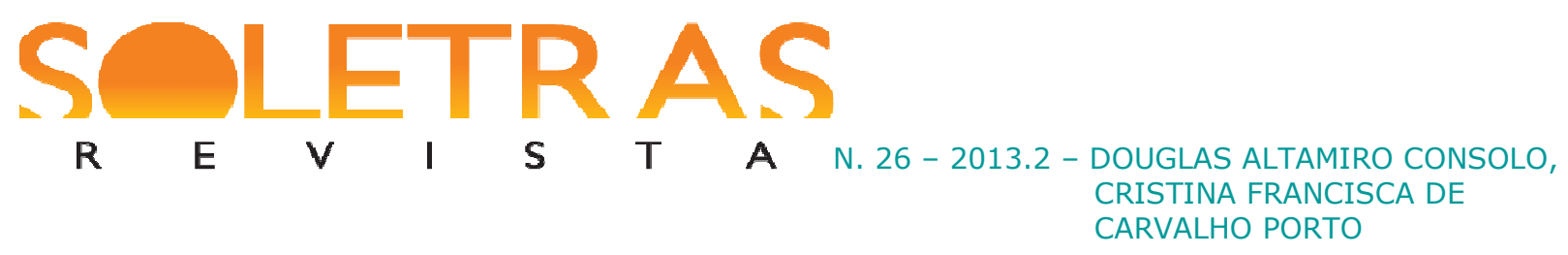

\title{
COMPETÊNCIAS DOCENTES NA PERSPECTIVA DE PROFESSORES DE LÍNGUAS ESTRANGEIRAS
}

\author{
Douglas Altamiro Consolo ${ }^{1}$ \\ Universidade do Estado de São Paulo \\ Cristina Francisca de Carvalho Porto ${ }^{2}$ \\ Centro de Línguas de São José do Rio Preto
}

\begin{abstract}
Resumo: O presente artigo tem como objetivo tecer algumas considerações acerca das competências docentes sob a perspectiva de um grupo de professores de línguas da rede pública. Adotamos como principal base teórica os textos de Paulo Freire (2001), Philippe Perrenoud (2002), Edgar Morin (2003) e Maurice Tardif (2002), e a partir destes textos fazemos algumas reflexões tomando como ponto de partida questões respondidas por professores de línguas. Durante um curso de extensão oferecido aos professores, lançamos a questão-base do nosso estudo: quais competências são necessárias para que um professor seja considerado um bom profissional na atualidade? A partir das respostas dadas individualmente e de discussões em grupo, realizamos uma análise comparativa em relação à teoria adotada, além de outros questionamentos acerca da formação dos professores. Todos os participantes apontaram as mesmas duas competências: o uso de novas tecnologias e o domínio do conteúdo ensinado. Outras competências também foram mencionadas pelos diferentes professores. Tal exercício, além de fornecer subsídios para nosso estudo, também serviu como uma autoavaliação, um exercício reflexivo dos professores em relação à própria atuação. Esperamos, a partir dos questionamentos elencados nos textos e das respostas dos professores, revisitar as competências necessárias para se atuar com eficácia no ofício de professor de línguas estrangeiras.
\end{abstract}

Palavras-chave: Competência docente. Formação de professores. Prática reflexiva. Ensino de línguas.

\section{Introdução}

\footnotetext{
${ }^{1}$ Doutor em Linguística Aplicada / TEFL - The University of Reading, Inglaterra (1996) e Livre-Docente em Língua Inglesa pela UNESP (2004). Atualmente é Professor Adjunto - Nível III, em RDIDP, da UNESP, atuando nas áreas de Linguística Aplicada, com ênfase em Ensino Aprendizagem de Línguas Estrangeiras, e Língua Inglesa. Coordena o grupo de pesquisa "Ensino e Aprendizagem de Língua Estrangeira: crenças, construtos e competências" (ENAPLE-CCC) desde 2002. E-mail: dconsolo@terra.com.br.

${ }^{2}$ Doutora em Letras pela UNESP (2007), atualmente atua como Coordenadora Pedagógica no Centro de Estudo de Línguas de São José do Rio Preto. Professora Efetiva de Língua Portuguesa da rede pública estadual de São Paulo. Desenvolveu estágio de Pós-Doutorado na área de Formação de Professores e Prática Docente no IBILCE/UNESP em 2012. Atua no Gample - Grupo de Pesquisa Multidisciplinar: Pesquisa Linguística e Ensino, desde 2008. E-mail: crisfcporto@gmail.com.
} 
Nosso principal objetivo neste artigo é tecer algumas considerações acerca das competências docentes da atualidade. Para tanto, foi oferecido um curso de extensão aos professores de um Centro de Estudos de Línguas do estado de São Paulo, em que foram discutidas as competências necessárias para se exercer com eficácia o ofício de docente de línguas estrangeiras. Durante o curso, lançamos a questão: quais competências são necessárias para que um professor seja considerado um bom profissional na atualidade? E a partir das respostas dadas realizamos a análise aqui apresentada.

Para a realização deste estudo, adotamos como base teórica estudos acerca das competências docentes e formação de professores apresentadas pelos teóricos resenhados a seguir.

Paulo Freire (2001) aponta os saberes necessários à prática educativa-crítica, fundamentada na ética e alicerçada na pesquisa. Segundo o autor, sem autonomia não há prática de ensino e nem aprendizagem, a competência técnico-científica deve ser inerente ao professor, pois o discurso competente em si mesmo não resolve as questões da educação escolar se a ação pedagógica não for aberta a mudanças.

Philippe Perrenoud (2002) considera que para ser competente o professor deve ter conhecimento, ter habilidade de colocar o saber em prática e ter atitude positiva no que se refere à iniciativa e desenvolvimento do trabalho e à sua realização com eficiência. A partir desta ideia, ele organizou dez grandes famílias de competência docente: organizar e dirigir situações de aprendizagem; administrar a progressão das aprendizagens; conceber e fazer evoluírem os dispositivos de diferenciação; envolver os alunos em suas aprendizagens e em seu trabalho; trabalhar em equipe; participar da administração da escola; informar e envolver os pais; utilizar novas tecnologias; enfrentar os deveres e os dilemas éticos da profissão e administrar sua própria formação contínua.

Edgar Morin (2003) apresenta temas que enriquecem o debate sobre os saberes necessários aos docentes. Em uma visão multidisciplinar da educação escolar, este autor colocou suas principais ideias sobre a educação do amanhã na obra "Os sete saberes necessários à Educação do Futuro" (2003), dividida em: As cegueiras do conhecimento: o erro e a ilusão; Os princípios do conhecimento pertinente; Ensinar a condição humana; Ensinar a identidade terrena; Enfrentar as incertezas; Ensinar a compreensão e A ética do gênero humano. 
Maurice Tardif (2002) aborda questões mais inquietantes para a docência ao falar da carência dos mestres, do problema econômico, das diferenças de tratamento em comparação a outras profissões; trata também da falta de valorização dos profissionais da educação. Segundo Tardif, o saber docente está relacionado com a prática e formação profissional, com os saberes da ciência da educação, com a identidade de cada um. E assim, ele propõe questões inquietantes como: quais saberes são mais importantes? Quais conhecimentos devem ser desenvolvidos? Quais competências e habilidades são melhores? E como resposta a estas questões ele apresenta quatro saberes docentes necessários: Saberes da formação profissional, Saberes da disciplina, Saberes curriculares e Saberes experienciais.

A análise aqui empreendida tem como fundamentação teórica não apenas os teóricos acima mencionados, precursores da maioria dos trabalhos que hoje lemos sobre a formação de professores, como também outros estudos relacionados à competência e saberes docentes tais como Roza (2008), Contreras (2002), Imbernom (2011), Schön (2000) e Alarcão (2003). Vale lembrar que Consolo e Porto (2012) também realizaram um estudo sobre as competências docentes na atualidade utilizando a mesma base teórica supracitada nesta introdução. Neste artigo, os autores, além de apresentarem com mais detalhes os teóricos aqui mencionados, apresentando definições mais detalhadas acerca das competências docentes, também os relacionam com a definição de abordagem apresentada por Almeida Filho (1993, 1999 e 2004) acerca das competências necessárias para os professores de línguas na atualidade.

Procuramos neste artigo delimitar, por meio de uma análise comparativa, as competências exigidas do professor no panorama atual, para que este seja um bom profissional e atenda com o esperado pelas instituições de ensino e por seus alunos. E, o mais importante, munido de informações e estratégias mais atualizadas, o docente possa ter autonomia e segurança no exercício de sua profissão.

\section{Competências docentes na perspectiva de professores de línguas estrangeiras}

Durante a realização deste estudo, convidamos um grupo de professores de línguas que se dispuseram a participar da realização desta pesquisa fazendo a leitura dos textos sobre as competências docentes apresentadas por Freire, Perrenoud, Morin e Tardif.

Foi oferecido aos professores um curso de extensão intitulado "Competências necessárias ao professor de línguas estrangeiras na atualidade", de trinta e duas horas, 


\section{$\begin{array}{llllllll}\mathbf{R} & \mathbf{E} & \mathbf{V} & \mathbf{I} & \mathbf{S} & \mathbf{T} & \mathbf{A} & \text { N. } 26-2013.2-\text { DOUGLAS ALTAMIRO }\end{array}$ \\ CONSOLO, CRISTINA \\ FRANCISCA DE CARVALHO PORTO}

distribuídas em oito encontros. Durante o curso, foram realizadas algumas etapas desta pesquisa. Iniciamos dando a eles liberdade para expressarem suas emoções e, principalmente, reclamações sobre problemas salariais, falta de estrutura e de material para trabalhar; em seguida fizemos o primeiro exercício, que foi responder a questão sobre as competências, e optamos por iniciar com a pergunta antes da leitura de textos para que os professores não fossem influenciados pelas teorias antes do processo da coleta de dados.

Nos demais encontros, foram feitas as leituras e discussões acerca das teorias sobre as competências docentes. Durante as discussões, os professores diziam que estas teorias só serviam para países europeus em que os problemas na educação não são graves como os do Brasil, e então, para tentar modificar essa impressão, foi mostrado a eles o filme Entre os muros da escola, de Laurent Cantet. Os professores então perceberam que as realidades eram bem parecidas com as nossas. Continuamos com as leituras teóricas, e mostrou-se a eles o outro filme, "Ser e Ter", de Nicolas Philibert, a partir do qual foi possível comparar uma boa prática pedagógica com a do filme anterior, que era bem conflitante. Por último, eles fizeram uma autoavaliação sobre as competências docentes apresentadas durante o curso.

Passamos agora à apresentação do grupo (cujos nomes foram substituídos pelas siglas P1, P2, P3, P4, P5, P6, P7 e P8) e dos dados levantados durante o curso para a realização desta pesquisa.

O grupo era formado por oito professores, todos com licenciatura em Letras e atuando no ensino de línguas. Dentre os professores, apenas dois frequentaram a graduação em faculdades particulares, P3 e P5, os demais são formados em universidades públicas. Temos cinco professores que atuam no ensino da língua espanhola, P1, P2, P3, P6 e P7, um atua na língua inglesa, P5, um na língua italiana, P8, e um na língua francesa, P4. Quanto ao tempo de atuação, temos P5 com três anos no magistério e os demais professores possuem entre quinze a vinte anos de atuação no ofício docente. Todos lecionam na rede pública estadual, sendo que P1 e P6 também lecionam em escolas particulares.

No início de nossa discussão, que foi realizada em grupo, e antes mesmo das leituras dos textos ou de assistirem aos filmes, os professores responderam a questão-base desta pesquisa: quais competências são necessárias para que um professor seja considerado um bom profissional na atualidade?

As respostas que transcrevemos a seguir foram escritas pelos professores, individualmente: 


\section{T N. 26 - 2013.2 - DOUGLAS ALTAMIRO

\section{P1}

Criatividade, tolerância, domínio das novas tecnologias, dinamicidade, autonomia, organização, preocupação com o aprendizado do aluno, ajudar o aluno na construção do seu aprendizado com autonomia, domínio dos conteúdos, aberto ao trato com os alunos, educação e diplomacia, ajudar o aluno a desenvolver-se no âmbito pessoal e acadêmico.

\section{P2}

Domínio das novas tecnologias, formação continuada, preparação de aulas dinâmicas e criativas, planejar aulas que prendam a atenção dos alunos, preparar exercícios extras e de auxílio, ter organização na aula e no material, dominar o conteúdo, pesquisar assuntos relevantes às matérias (conteúdos) estudados, atividades além do livro didático e da sala de aula.

\section{P3}

Domínio das novas tecnologias, criatividade, formação continuada, dinâmico, saber os conteúdos, ser organizado, preparar as aulas com pesquisas, ter um bom relacionamento com os alunos.

\section{P4}

Estar atualizado e informado, domínio das novas tecnologias, formação continuada, ser dinâmico, criativo, domínio de conteúdo, organização, preparação de aulas. O professor de línguas estrangeiras deve ter habilidades nas quatro competências, ter fluência.

\section{P5}

Para que um professor seja considerado um bom profissional na atualidade é necessário que o mesmo possua as seguintes competências:

- Ter sensibilidade - isso significa sentir a aula, os alunos, os eventos, para que a aula seja agradável e voltada às necessidades dos alunos;

- Dominar o conteúdo - se os alunos percebem que o professor não conhece a fundo a matéria, perdem o respeito e a vontade;

- Ensinar o grupo e os indivíduos - além de conduzir o grupo, o professor deve atender as necessidades individuais de aprendizagem de cada aluno;

- Conhecer e utilizar as novas tecnologias - tornando a aula mais atraente e identificada com o aluno atual;

- Saber avaliar - não significa aplicar provas ou avaliações nos moldes antigos, mas avaliar realmente o progresso continuamente, corrigindo a metodologia e a didática;

- Utilizar o conhecimento prévio do aluno - nunca desprezar o conteúdo que cada um traz;

- Ter amor pelo ensino e pelos alunos - quando os alunos sentem que o professor os ama, consequentemente os respeita e ensina, eles oferecem aquilo que têm de melhor no processo de ensino-aprendizagem.

\section{P6}

Domínio das novas tecnologias para serem usadas com os conteúdos do currículo escolar; domínio dos conteúdos do material escolar; planejar as aulas e avaliações e seguir o cronograma proposto; saber trabalhar com a heterogeneidade das salas de aula em relação ao processo de aprendizagem

SOLETRAS, N. 26 (jul.-dez. 2013)

ISSN: $2316-8838$

DOI: $10.12957 /$ soletras.2013.7071 


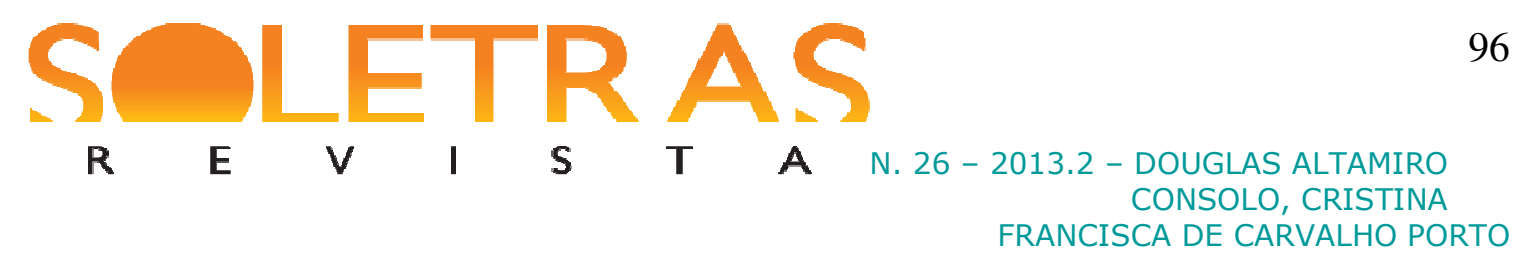

dos alunos; fazer com que os alunos façam atividades fora do espaço escolar; fazer com que os alunos façam atividades de produção oral durante as aulas.

\section{P7}

São necessárias as seguintes competências: saber fazer, saber aprender, saber: ter paciência, domínio de conteúdo, organização, usar as novas tecnologias, ser pacificador nas situações difíceis, ter jogo de cintura para reinventar as situações.

\section{P8}

Domínio das novas tecnologias, ter paciência, dinâmico, ser criativo, ser equilibrado, domínio de conteúdo, ser organizado, saber elaborar um plano de aula, ser comunicativo, ter empatia, ser mediador, ser carismático.

Dentre todas as respostas acima, duas competências foram citadas por todos os docentes, são elas: o uso de novas tecnologias e o domínio do conteúdo ensinado.

Realmente, em nossa época, o uso de tecnologias se faz indispensável na educação, e neste aspecto não há como negar que falta muito a ser feito para que esta competência realmente atinja todos os docentes, pois quando se tem estrutura material não há o conhecimento teórico, muitos docentes não se sentem preparados e não têm apoio para utilizar nenhum tipo de tecnologia em suas aulas.

A forma como as tecnologias devem ser inseridas e utilizadas na educação ainda causa muita discussão entre aqueles que são adeptos e aqueles que a repudiam. Conforme afirma Perrenoud (2000, p. 126)

Nada dizer a respeito das novas tecnologias em um referencial de formação contínua ou inicial seria indefensável.

[...]

O referencial aqui referido escolheu quatro entradas bastante práticas:

- Utilizar editores de textos.

- Explorar as potencialidades didáticas dos programas em relação aos objetivos do ensino.

- Comunicar-se à distância por meio da telemática.

- Utilizar as ferramentas multimídia no ensino.

Essas competências concernem ao professor, porém é difícil dissociá-las completamente da questão de saber que formação em informática ele deve dar aos alunos.

O autor, apesar de não querer colocar o uso das tecnologias em destaque em relação às demais competências, sabe de sua importância inegável e das dificuldades de sua utilização pelos professores, pois sempre há os que se recusam. É interessante notar que este texto de 


\section{R $\quad \mathbf{V}$ S $\quad$ T A N. 26-2013.2- DOUGLAS ALTAMIRO

Perrenoud foi escrito há mais de dez anos e ainda temos, atualmente, professores que ou não sabem nada de informática, ou, se sabem, não gostam de utilizá-la. Há ainda aqueles que nem ao menos têm um e-mail para se comunicar. Assim, acreditamos que o desafio maior não é mais o que o autor citou acima, como dar esta formação em informática aos alunos, pois estes já nos ultrapassaram muito. O que nos falta é conseguir formação prática para o professor de como utilizar esses recursos didaticamente, enriquecendo sua aula e favorecendo a aprendizagem de seus alunos.

Perrenoud (2000, p. 131-132) afirma ainda que

É pouco provável que o sistema educacional imponha autoritariamente aos professores em exercício o domínio dos novos instrumentos, ao passo que, em outros setores, não se abrirá mão desse domínio. [...] A evolução da mídia, do comércio eletrônico e a generalização dos equipamentos familiares tornarão o acesso cada vez mais banal, sem que as competências requeridas se desenvolvam no mesmo ritmo. É por isso que a responsabilidade da escola está comprometida para além das escolhas individuais dos professores.

Com certeza, ainda que a instituição de ensino não obrigue seus professores a utilizarem, dominarem as tecnologias, o espaço exterior o faz, a sociedade pressiona para que isto aconteça:é algo que realmente ultrapassa os limites da escola. Os próprios alunos acabam exigindo de seus professores aulas mais dinâmicas, que incluam a utilização de recursos tecnológicos. E, também, os professores já reconhecem esta competência como algo fundamental para um docente, como vimos nas respostas da pesquisa, em que a maioria apontou a necessidade do domínio das novas tecnologias.

O domínio do conteúdo foi outra competência citada por todos os participantes de nossa pesquisa, o que demonstra que realmente ter conhecimento sobre o que é ensinado é fundamental. Para Freire (2001), este conhecimento implica em uma segurança necessária para complementar a competência profissional do docente.

A segurança com que a autoridade docente se move implica uma outra, a que se funda na sua competência profissional. Nenhuma autoridade docente se exerce ausente desta competência. O professor que não leve a sério sua formação, que não estude, que não se esforce para estar à altura de sua tarefa não tem força moral para coordenar as atividades de sua classe (FREIRE, 2001, p. 91). 
O autor apresenta competência profissional como fundamental para o ofício docente, sem a qual nenhuma outra competência será possível. Freire salienta ainda a importância do professor cuidar de sua formação e estudar, esforçando-se assim para bem exercer suas atividades. Porém, o próprio autor reconhece que só o domínio dos conteúdos não basta: “Assim como não posso ser professor sem me achar capacitado para ensinar certo e bem os conteúdos de minha disciplina, não posso, por outro lado, reduzir minha prática docente ao puro ensino daqueles conteúdos" (FREIRE, 2001, p. 103).

Verificamos que a maioria também acha que ser organizado é importante. P1, P2, P3, P4, P7 e P8 citaram esta competência em suas respostas. Esta é uma competência mais administrativa do que pedagógica, visto que as instituições geralmente reconhecem como organizado aquele professor que mantém registro diário de suas atividades, cumpre todos os prazos para entrega de notas e frequência de seus alunos, segue os planos de aula e projetos estabelecidos pelos gestores da escola. Aquele docente que não acha importante ter organização geralmente também é o que trabalha no improviso e só repassa as informações do seu trabalho depois dos prazos vencidos. É importante salientar que esta atitude pode ser muito prejudicial ao docente, sobretudo em instituições privadas, pois ele pode inicialmente ser advertido e, em caso de persistência do problema, ser dispensado da instituição.

Outra competência muito citada foi a criatividade: P1, P2, P3, P4 e P8 citaram esta competência como importante para preparação de aulas mais dinâmicas. Não há dúvida de que a criatividade é um aspecto importante como ferramenta para melhorar as aulas, sobretudo quando estamos diante de situações imprevistas, em que se faz necessário o improviso e, mais ainda por se tratar de um trabalho com jovens, na sua maioria inquietos e que rapidamente se entediam com as atividades. A criatividade docente está diretamente ligada às escolhas que este faz. Tardif (2002, p. 132) chama atenção para o fato de que "ensinar é fazer escolhas constantemente em plena interação com os alunos e tais escolhas dependem da experiência dos professores, de seus conhecimentos, convicções e crenças, de seu compromisso com o que fazem, de suas representações a respeito dos alunos".

P1, P3, P4, P7 e P8 consideram importante que o professor seja dinâmico, isto é, tenha "jogo de cintura" durante suas aulas, saiba improvisar para resolver situações inesperadas. Esta competência também está, a nosso ver, ligada à questão que abordamos anteriormente acerca das escolhas e da criatividade dos professores. O professor dinâmico consegue despertar a curiosidade de seus alunos e o desejo de aprender. 
Quatro professores, P1, P3, P5 e P8, acham importante para ser um bom professor que este se preocupe com seus alunos, tenha sensibilidade e preocupação com a aprendizagem dos mesmos, tenha amor tanto pelo ensino quanto por seus alunos. É o que Freire (2000, p. 141) chama de "querer bem aos educandos".

Esta abertura ao querer bem não significa, na verdade, que, porque professor, me obrigo a querer bem a todos os alunos de maneira igual. Significa, de fato, que a afetividade não me assusta, que não tenho de expressá-la. Significa esta abertura ao querer bem a maneira que tenho de autenticamente selar o meu compromisso com os educandos, numa prática específica do ser humano. Na verdade, preciso descartar como falsa a separação radical entre seriedade docente e afetividade. [...] O que não posso obviamente permitir é que minha afetividade interfira no cumprimento ético de meu dever de professor no exercício de minha autoridade.

Portanto, é preciso gostar de seus alunos, sem que este gostar interfira de modo prejudicial em suas atividades e, sobretudo, nas avaliações. Um limite entre a afetividade e o profissionalismo deve sempre ser mantido.

Quanto à formação continuada, somente três professores acham que seja importante, P2, P3 e P4. Esta é uma questão muito discutida atualmente pois, enquanto alguns especialistas dizem que o professor deve ser responsável por sua formação, outros dizem que cabe à instituição de ensino promover, dentro do espaço de trabalho, um momento para esta formação. Na verdade, acreditamos que ambos têm razão, pois se os dois lados buscarem se comprometer com a formação continuada, com certeza o ensino nesta instituição será de melhor qualidade.

Segundo Morin (2002, p. 31), "o conhecimento do conhecimento, que comporta a integração do conhecedor em seu conhecimento, dever ser, para a educação, um princípio e uma necessidade permanentes". Para o autor, é evidente que cada docente seja capaz de se engajar a favor de sua própria formação a partir das oportunidades de aprendizagem e aperfeiçoamento que lhes são fornecidos.

Para Imbernón (2011, p. 23), “a instituição educativa, como conjunto de elementos que intervêm na prática educativa contextualizada, deve ser o motor da inovação e da profissionalização". Ou seja, o autor credita a responsabilidade para a instituição de ensino, pois, segundo ele, se feita de forma individual, a formação perde um importante valor de melhoria coletiva, tornando-se meramente experiência pessoal. 
Na Lei de Diretrizes e Bases da educação brasileira, o assunto da formação docente é tratado desde a formação inicial do professor até sua formação continuada após concluir sua licenciatura, sendo o assunto exposto da seguinte maneira:

\section{TÍTULO VI}

Dos Profissionais da Educação

Art. 61. A formação de profissionais da educação, de modo a atender aos objetivos dos diferentes níveis e modalidades de ensino e às características de cada fase do desenvolvimento do educando, terá como fundamentos: (Regulamento)

I - a associação entre teorias e práticas, inclusive mediante a capacitação em serviço;

II - aproveitamento da formação e experiências anteriores em instituições de ensino e outras atividades.

[...]

Art. 63. Os institutos superiores de educação manterão: (Regulamento)

I - cursos formadores de profissionais para a educação básica, inclusive o curso normal superior, destinado à formação de docentes para a educação infantil e para as primeiras séries do ensino fundamental;

II - programas de formação pedagógica para portadores de diplomas de educação superior que queiram se dedicar à educação básica; III programas de educação continuada para os profissionais de educação dos diversos níveis.

[...]

Art. 67. Os sistemas de ensino promoverão a valorização dos profissionais da educação, assegurando-lhes, inclusive nos termos dos estatutos e dos planos de carreira do magistério público:

I - ingresso exclusivamente por concurso público de provas e títulos;

II - aperfeiçoamento profissional continuado, inclusive com licenciamento periódico remunerado para esse fim;

III - piso salarial profissional;

IV - progressão funcional baseada na titulação ou habilitação, e na avaliação do desempenho;

V - período reservado a estudos, planejamento e avaliação, incluído na carga de trabalho;

VI - condições adequadas de trabalho.

Conforme a LDB, as instituições de ensino superior podem oferecer essa formação não apenas inicial, como também a continuada; é direito do professor ter garantido, em seu local de trabalho, período para essa formação. Atualmente, notamos um avanço neste sentido, pois as secretarias de educação tanto municipais quanto estaduais têm feito parcerias com as universidades para oferecer essa formação a seus docentes, porém, em alguns casos, sobretudo na esfera estadual, os cursos de capacitação não são oferecidos dentro do horário de trabalho do professor, mas em outros horários, o que faz com que muitos não queiram 
participar por considerarem este tipo de prática como trabalho extra não remunerado. Assim, a formação acaba não atingindo a todos os docentes, e o sistema de formação continuada é falho, gerando desigualdade entre os sistemas de ensino.

Em relação à pesquisa para melhorar o ensino ou sua própria formação, somente P2 e P3 acham que seja importante. Nota-se que a grande maioria dos professores não acredita na importância da pesquisa para seu enriquecimento profissional. Neste grupo de oito docentes, seis possuem curso de especialização em sua área e dois não, nenhum possui mestrado ou doutorado e também não demonstraram interesse em fazê-lo, devido a falta de valorização dos títulos dentro de suas instituições de ensino.

No aspecto das competências, a pesquisa é um elemento de fundamental importância e que deve fazer parte do cotidiano do professor. Ela deve ser assumida por este como elemento norteador de sua atividade docente. Segundo Roza (2008, p. 27)

Demo (1998) desafia os professores a assumirem a pesquisa como atitude cotidiana, onde o questionamento reconstrutivo ganha espaço em sala de aula. Significa dizer que o espaço pedagógico da sala de aula precisa ganhar vida, ser redimensionado para constituir-se em um lugar onde educador e educandos possam refletir, discutir, reconstruir seus saberes, gerar aprendizagens significativas.

Conforme o autor, é dentro da sala de aula que a pesquisa encontra seu laboratório e deve ser aplicada e vivenciada, o processo investigativo resulta em um protagonismo entre professor e alunos, transformando o trabalho do professor em uma atividade interativa.

Uma competência importante ao professor e que foi citada uma única vez é a autonomia, tanto do professor quanto do aluno, somente P1 citou este aspecto em sua resposta.

Freire foi um dos estudiosos da educação que mais defendeu a autonomia. Segundo ele, é uma competência que se constrói aos poucos, de acordo com as decisões que você toma no seu dia-a-dia:

A gente vai amadurecendo todo dia, ou não. A autonomia, enquanto amadurecimento do ser para si é processo, é vir a ser. Não ocorre em data marcada. É neste sentido que uma pedagogia da autonomia tem de estar centrada em experiências estimuladoras da decisão e da responsabilidade, vale dizer, em experiências respeitosas da liberdade (FREIRE, 2001, p. 107). 
A construção da autonomia implica em liberdade de escolha, liberdade na tomada de decisões e, segundo o autor, esta liberdade deve estar presente em todo processo educativo para que o aluno tenha condições de crescer não apenas em termos de conhecimento, mas sobretudo como pessoa no mundo. Para o professor, a autonomia é importante no sentido de que lhe fortalece, dando maior segurança em sua prática diária; ele se torna mais independente e tem a possibilidade de dar rumos mais específicos e adequados para cada turma. Enquanto Freire aponta uma autonomia que se desenvolve aos poucos no fazer docente, Contreras (2002) destaca três modelos de professores e a cada um atribui uma concepção de autonomia. Assim, temos: para o perfil de Especialista Técnico, autonomia como status ou como atributo. Autoridade unilateral do especialista. Não ingerência. Autonomia ilusória. Dependência de diretrizes técnicas, insensibilidade para os dilemas, incapacidade de resposta criativa diante da incerteza; para o perfil de Profissional Reflexivo, autonomia como responsabilidade moral individual, considerando os diferentes pontos de vista. Equilíbrio entre a independência de juízo e a responsabilidade social. Capacidade para resolver as situações-problema para a realização prática das pretensões educativas; e, por fim, para o perfil de Intelectual Crítico, autonomia como emancipação: liberação profissional e social das opressões. Superação das distorções ideológicas. Consciência crítica. Autonomia como processo coletivo (configuração discursiva de uma vontade comum), dirigido à transformação das condições institucionais e sociais de ensino.

Com base nas concepções de autonomia apontadas por Contreras, entendemos que um equilíbrio entre as duas últimas é o desejável para o perfil ideal de um docente, sobretudo àquele que atua na rede pública de ensino, visto que geralmente as instituições particulares exigem um perfil docente mais específico e de acordo com a metodologia adotada por cada escola.

Somente P5 citou como competência importante ao bom professor o trabalho em grupo, atendimento às necessidades individuais de cada aluno e o trabalho com o conhecimento prévio do grupo. As respostas de P5 se mostraram muito mais direcionadas às questões relativas aos alunos, como a aprendizagem e o relacionamento com eles. Este professor em nenhum aspecto se mostrou preocupado com seus pares ou com a instituição de ensino, nem tampouco com sua formação. 
P6 deu respostas mais ligadas ao conteúdo, utilização de materiais e aplicação destes em sala de aula, e também não mostrou preocupação com outros aspectos ligados à instituição, ao trabalho com os demais professores ou com sua formação.

Verificamos nas respostas deste grupo de professores que à exceção de um ou outro, cuja resposta foi mais específica em relação a determinado aspecto que o agrada mais, a grande maioria dos docentes tem consciência de seu papel, de seus deveres enquanto profissional do magistério e, principalmente, das competências necessárias para uma boa atuação.

Os professores sabem o que devem buscar para exercer sua atividade docente com qualidade, haja visto que nos deram respostas que correspondem com as teorias apresentadas acerca dos saberes docentes.

Este exercício pode ser visto como uma autoavaliação e é interessante de ser aplicado aos professores, pois faz com que estes reflitam sobre sua atuação, sua prática, um processo importante para rever e atualizar seu posicionamento diante do ensino. Acerca do ato reflexivo, Schön (2000, p. 31) afirma:

[...] é possível através da observação e da reflexão sobre nossas ações, fazermos uma descrição do saber tácito que está implícito nelas. Nossas descrições serão de diferentes tipos, dependendo de nossos propósitos e das linguagens disponíveis para essas descrições

Percebe-se que esta concepção de uma reflexão sobre a prática nos leva a uma série de transformações em nosso perfil enquanto profissional, cuja reflexão conduz a um pensamento crítico, permite-nos identificar a atual situação de nossa prática docente, assim como identificar o que está sendo construído por nossos alunos durante este processo de ensino. Tal ato reflexivo também gera uma consequente mudança de atitude profissional.

A construção de uma prática reflexiva permite a reformulação de conceitos, assim como uma participação mais ativa e contestadora do docente sobre sua própria ação, afastando-o da posição de mero transmissor de conteúdos.

A partir deste exercício de reflexão, o professor tem condições de desenvolver uma prática mais significativa, mais coerente não apenas com seu perfil de educador, mas também com a realidade de seus alunos. Segundo Alarcão (2003, p. 41), 


\section{A N. $26-2013.2$ - DOUGLAS ALTAMIRO CONSOLO, CRISTINA \\ FRANCISCA DE CARVALHO PORTO}

[...] a noção de professor reflexivo baseia-se na consciência da capacidade de pensamento e reflexão que caracteriza o ser humano criativo e não como mero reprodutor de ideias e práticas que lhe são exteriores. É central, nesta conceptualização, a noção do profissional como uma pessoa que, nas situações profissionais, tantas vezes incertas e imprevistas, actua de forma inteligente e flexível, situada e reactiva.

Certamente, é este o perfil do bom profissional e este deve ver tal prática como um suporte à sua atuação, algo que lhe possibilite mudar, unindo o seu conhecimento teórico à sua prática pedagógica não por considerá-la como uma meta de avaliação para ser relatada aos seus superiores, e sim como algo que realmente o faça conceber melhoras em suas aulas, fornecendo novos aparatos e novas visões à sua atividade docente.

\section{Considerações finais}

As questões respondidas pelos professores serviram de base para uma reflexão necessária acerca dos saberes docentes. Quando no início deste estudo lançamos a questão quais competências são necessárias para que um professor seja considerado um bom profissional na atualidade? Não esperávamos realmente chegar a uma resposta objetiva, simples e clara. Esta resposta não existe porque ela varia conforme vários aspectos, a começar pelo que a instituição de ensino almeja dos seus docentes, qual a estrutura oferecida para que seus professores consigam desenvolver as competências; segundo, depende do que os gestores julgam como primordial em seus educadores; terceiro, qual tipo de imagem eu, enquanto professor, quero passar para meus alunos; e, ainda, o que a sociedade espera de mim enquanto educador no século XXI.

Tratamos aqui de temas que são muito recorrentes nos discursos pedagógicos e que são amplamente discutidos, pois são temas diretamente ligados à busca por uma educação de qualidade. Assim sendo, foi preciso delimitar o campo teórico e optamos por trabalhar somente com os precursores, principalmente os mais adotados nas pesquisas acerca do assunto. O intuito é, sobretudo, lançar novos pontos para outras reflexões e ações no campo da formação de professores.

Se um professor perguntar o que é necessário para atuar com eficácia, em primeiro lugar a resposta seria: gostar do que faz, pois todas as demais competências se desenvolverão mais 


\section{R $\quad \mathbf{V}$ T $\quad$ T $\quad$ A N. 26-2013.2- DOUGLAS ALTAMIRO \\ CONSOLO, CRISTINA \\ FRANCISCA DE CARVALHO PORTO}

facilmente, em consequência desse gosto pela profissão. Sobre o que fazer para alcançar as competências necessárias, a sugestão é a seguinte: leia a obra de Paulo Freire para compreender que educar exige generosidade, ética e respeito ao educando; leia Philippe Perrenoud para saber organizar o processo de ensino e sua prática; leia Maurice Tardif para buscar a profissionalização de seu ofício e se valorizar enquanto profissional, e, por último, leia Edgar Morin para entender como ensinar o respeito pela condição humana na sua totalidade, fazendo a ligação dos saberes ensinados com a construção do indivíduo enquanto cidadão do mundo. Certamente, a partir da leitura das obras destes estudiosos, teremos contato ainda com outras teorias, ambas unidas à nossa prática pedagógica, assimiladas e a ela adaptadas, que conduzirão a uma melhoria significativa da aprendizagem de nossos alunos.

Acompanhando esta linha de estudo, procuramos mostrar não apenas aos futuros professores, mas àqueles que já atuam no magistério que, para ser um bom profissional, é possível, por meio de leituras, trocas de experiências, cursos de formação contínua e de um hábito reflexivo sobre a própria prática docente, atingir este mérito. Não podemos mais pensar que bons professores são apenas os que têm o "dom" ou "talento", ou seja, que já nasceram para ser professor, como julgam algumas crenças. A profissionalização do docente é resultado de um processo conjunto entre formadores das universidades, alunos de licenciaturas, docentes e instituições de ensino. Somente a própria prática permitirá aos professores desenvolverem suas competências e, ainda, tendo um professor engajado com sua instituição, comprometido com seu contexto escolar e com seu grupo, certamente haverá qualidade na educação oferecida.

\section{Referências bibliográficas:}

ALMEIDA FILHO, J. C. P. Dimensões comunicativas no ensino de línguas. Campinas, SP: Pontes, 1993.

(Org.) O professor de língua estrangeira em formação. Campinas, SP: Pontes, 1999.

O professor de língua(s): profissional, reflexivo e comunicacional. Horizontes de Lingüística Aplicada, v. 3, n. 1, p. 7-18, 2004.

ALARCÃO, I. Professores reflexivos em uma escola reflexiva. São Paulo: Cortez, 2003.

BRASIL. Ministério da Educação e Cultura. Lei de Diretrizes e Bases da Educação. Brasília, 1996. 


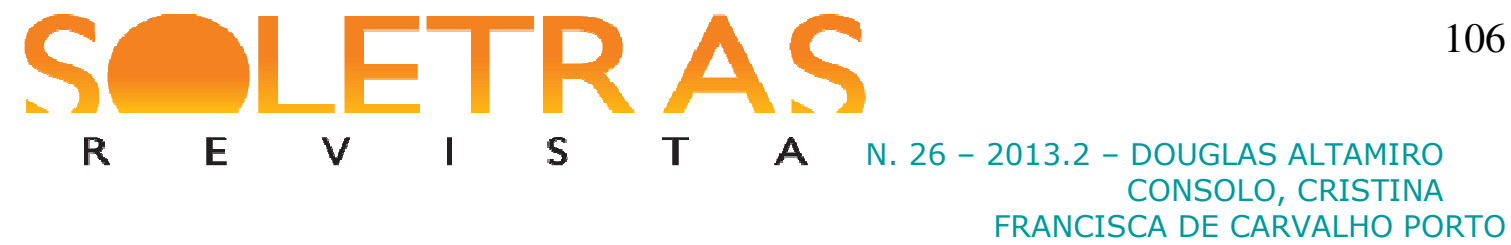

CONSOLO, D.A, PORTO, C.F.C. Competências do professor no processo de ensinoaprendizagem de língua estrangeira. Horizontes de Linguística Aplicada, Brasília, vol. 10, N. 2, out. 2012. Disponível em: <http://seer.bce.unb.br/index.php/horizontesla/article/view/5554>. Acesso em: 14 Jul. 2013.

CONTRERAS, J. Autonomia dos professores. São Paulo: Cortez, 2002.

FREIRE, P. Pedagogia da Autonomia: saberes necessários à prática educativa. 18. ed. Rio de Janeiro: Paz e Terra, 2001.

IMBERNÓN, F. Formação docente e profissional: formar-se para a mudança e a incerteza. 9. ed. São Paulo: Cortez, 2011.

MORIN, E. Os sete saberes necessários à educação do futuro. Tradução de Catarina Eleonora F. da Silva e Jeanne Sawaya. São Paulo: Cortez; UNESCO, 2003.

PERRENOUD, P . As competências para ensinar no século XXI: a formação dos professores e o desafio da avaliação. Porto Alegre: Artmed, 2002.

ROZA, J. P. Desafios da docência: algumas reflexões sobre a possibilidade de uma gestão pedagógica da pesquisa. In: KRONBAUER, S. C. G.; SIMIONATO, M. F. (Orgs.) Formação de professores: abordagens contemporâneas. São Paulo: Paulinas, 2008.

SCHÖN, D. Educando o profissional reflexivo: um novo design para o ensino e a aprendizagem. Porto Alegre: ARTMED, 2000.

TARDIF, M. Saberes docentes e formação profissional. Petrópolis, RJ: Vozes, 2002.

\section{Competences in the classroom in the perspectives of foreign language teachers}

Abstract: In this article we raise some considerations about teachers' competences, from the perspective of teachers in the Brazilian public sector. The theoretical framework includes articles by Paulo Freire (2001), Philippe Perrenoud (2012), Edgar Morin (2003) and Maurice Tardif (2002) and, based on these authors, we reflect upon issues concerning teachers' competences taking answers provided by the Brazilian language teachers as a departing point. In a teachers' course, followed by the same teachers, we posed the main question in our study: Which competences are necessary for a teacher to be considered a good professional at present? From the answers given individually and group discussions we proceeded to a comparative analysis with the adopted framework, and other issues concerning teachers' competences were considered as well. All the participants mentioned the same two competences, the use of technology and sound knowledge of the course content, and other competences were pointed out by the various teachers as well. Such procedure, besides providing data for our study, also helped as a self-reflexive activity for the teachers involved, 


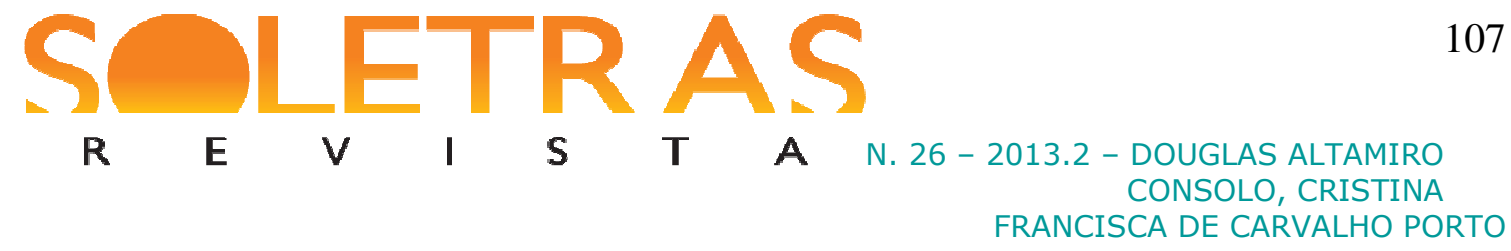

about their own professional performance. Given the issues raised in the theoretical texts and the answers provided by the teachers, we expect to revisit the competences necessary for foreign language teacher efficient performance.

Key words: Teachers' competences. Teacher education. Reflexive practice. Language teaching.

Recebido em: 08/08/2013.

Aprovado em: 08/01/2014. 